\title{
A UTILIZAÇÃO DO NEUROMARKETING NA FORMULAÇÃO DE ESTRATÉGIAS DE VENDAS MAIS EFICAZES
}

\author{
THE USE OF NEUROMARKETING IN THE FORMULATION OF MORE EFFECTIVE SALES \\ STRATEGIES
}

Iara Ramalho Rodrigues de Holanda Furtado (i)

Instituto de Educação Superior da Paraíba - UNIESP, PB, Brasil, iararhfurtado@gmail.com

Miriam Leite Farias

Universidade Federal de Pernambuco - UFPE, PE, Brasil, miriamlfarias@gmail.com

João Henriques de Sousa Júnior

Universidade Federal de Santa Catarina - UFSC, SC, Brasil, sousajunioreu@hotmail.com

DOI: http://dx.doi.org/10.31512/gesto.v8i2.113

Recebido em: 19/02/2020

Aceito em: 04/06/2020

\begin{abstract}
Resumo: A análise do comportamento dos consumidores sob uma perspectiva cerebral traz informaçóes valiosas para os profissionais de marketing. Dessa forma, o neuromarketing, disciplina que interliga as neurociências com o marketing, ganha força e destaque na área. Neste contexto, o presente ensaio teórico buscou refletir sobre possíveis estratégias de vendas baseadas nas teorias do neuromarketing, a partir de interligaçóes do poder do instinto, do emocional, do inconsciente e do subconsciente para o resultado em vendas. Constatou-se que: explorar os medos, ir além da comunicação verbal, compreender o poder do vocativo, e criar um vínculo com os clientes, são estratégias que podem contribuir de forma positiva para os resultados de vendas.
\end{abstract}

Palavras-chave: Marketing; Neuromarketing; Vendas.

Abstract: Analyzing consumer behavior from a cerebral perspective provides valuable information for marketers. Thus, neuromarketing, a discipline that links neuroscience with marketing, gains strength and prominence in the area. In this context, the present theoretical essay sought to reflect on possible sales strategies based on the theories of neuromarketing, from interconnections of the power of instinct, the emotional, the unconscious and the subconscious to the result in sales. It was found that: exploring fears, going beyond verbal communication, understanding the power of the vocative, and creating a bond with customers, are strategies that can positively contribute to sales results.

Keywords: Marketing; Neuromarketing; Sales.

\section{Introdução}

As descobertas das neurociências despertaram o interesse do estudo das atividades do cérebro humano em decorrência dos impactos do marketing na mente dos consumidores, tendo como um dos principais objetivos a compreensáo dos processos mentais de tomadas de decisóes. O conhecimento, por meio do rastreamento cerebral, permitiu o descobrimento de informaçóes relevantes para os profissionais 
de marketing e, como consequência, o neuromarketing ganhou destaque no mercado e nas pesquisas acadêmicas.

A análise do comportamento sob uma perspectiva cerebral permite identificar informaçóes "ocultas" no discurso implícito do consumidor (Ariely \& Berns, 2010). Sua importância se dá, principalmente, ao considerarmos que um alto percentual das decisóes de compra do consumidor acontece de forma inconsciente (Klaric, 2018). Assim, tais discursos implícitos terminam exercendo influências significativas na tomada de decisão de compra.

As teorias decorrentes das neurociências, como, por exemplo, a divisão do cérebro em três partes distintas, demonstraram o poder do instinto e da emoção para a tomada de decisão de compra. MacLean (1952) dividiu o cérebro em três: o reptiliano (ligado ao instinto), o límbico (voltado para a emoção) e o córtex (relacionado à razão). Tal divisão contribuiu para que estudos posteriores pudessem tentar compreender melhor o funcionamento do cérebro. Peruzzo (2015), por exemplo, indica que há momentos em que o cérebro é mais racional que emocional ou instintivo, enquanto Klaric (2018), afirma que a emoção anula a razão, mas o instinto anula os dois.

Apesar dessas descobertas, observou-se, que, mesmo com o crescimento de pesquisas científicas envolvendo o neuromaketing, a temática voltada à análise do assunto interligado ao resultado em vendas das empresas, principalmente decorrente da exploração dos cérebros reptiliano e límbico, ainda é incipiente e carece de publicaçóes e trabalhos científicos, considerando quantidade e profundidade de conteúdo.

Nesse sentido, este trabalho, que consiste de um ensaio teórico, tem como objetivo, embasado nas teorias de neuromarketing, refletir sobre a influência dos cérebros reptiliano e límbico para a obtenção de resultados de vendas, buscando, dessa forma, indicar o poder do inconsciente, do instinto e da emoção para o discurso de vendas de funcionários e apresentar estratégias de fáceis aplicaçóes para pequenas e médias organizaçóes. Acredita-se que as reflexôes trazidas neste estudo podem ser relevantes para a ampliação de estratégias gerenciais e, consequentemente, poderão trazer contribuições positivas nos resultados numéricos das vendas de empresas que utilizarem as informaçóes aqui expostas.

Para a execução deste trabalho expóe-se, incialmente, um panorama inicial do neuromarketing, abordando a interligação do marketing com as neurociências, apresentando conceitos e a importância da disciplina para pesquisas do comportamento do consumidor. Posteriormente, comenta-se sobre o comportamento dos consumidores sob uma perspectiva cerebral, identificado exemplos de técnicas e tecnologias de rastreamento do cérebro e apresentado a teoria dos três cérebros. Por fim, destaca-se a importância do inconsciente, do instinto e da emoção para os resultados em vendas, e apontam-se as descobertas sobre o tema, que poderão ser utilizadas como estratégias para a efetivação da compra.

\section{Um panorama sobre o neuromarketing}

O neuromarketing trata da aplicação de métodos neurocientíficos para compreender os processos inconscientes e as suas aplicações no Marketing (Bercea, 2013). Segundo a definição da Neurobusiness Association (2015), compreende um campo emergente que estuda a resposta sensorial, efetiva e cognitiva do consumidor. Para Garcia e Saad (2008), ao possuir um escopo teórico, empírico e prático, o neuromarketing assume o status de uma nova disciplina. A utilização do termo, por exemplo, surgiu de 
forma orgânica só por volta de 2002 (Morin, 2011). No entanto, como comentam Solnais et al. (2013), existe uma dificuldade para delimitar o neuromarketing como área do conhecimento, devido diversas influências de outras áreas.

Pelo pensamento de Morin (2011), o neuromaketing é a união de dois campos de estudo: a neurociência e o marketing, sendo a neurociência um campo interdisciplinar que envolve diversas outras disciplinas (Holley, 2006). Um dos focos da neurociência é a análise interna do cérebro para informar de que forma ocorrem os processos de escolhas dos consumidores (Chorvat \& McCabe, 2005).

Ainda que a utilização de técnicas psicofisiológicas para pesquisas sobre consumo não seja algo recente, o interesse da aplicação de técnicas neurocientíficas para o estudo de repostas cognitivas e emocionais do consumidor cresce em importância ao longo dos anos (Solnais et al., 2013). A sua importância se dá por meio da possibilidade de conectar, de maneira estratégica, os serviços, produtos, marcas ou categorias com a mente de consumidor (Klaric, 2018), e da utilização dos conhecimentos psicológicos-cognitivos, com base nas técnicas da neurociência, para o entendimento mais completo do comportamento de consumo (Boricean 2009). O pensamento de Ariely e Berns (2010) complementa a relevância da disciplina, uma vez que o neuromarketing tem o potencial de fornecer informaçóes que auxiliam a formulação mais efetiva de estratégias para aceitação de produtos, promovendo um melhor desempenho da marca no mercado.

\subsection{O comportamento dos consumidores sob uma perspectiva cerebral e evolutiva}

Conforme exposto anteriormente, a neurociência fornece informaçôes acerca da estrutura e das funçôes do cérebro, e seu objetivo envolve a compreensão dos mecanismos por trás de pensamentos, emoçôes, raciocínios e tomadas de decisão (Bercea, 2013). Promovendo, dessa forma, a oportunidade de compreender o comportamento do consumidor por meio de uma perspectiva cerebral (Morin, 2011). Com a utilização desta ciência, altamente interligada aos avanços tecnológicos e da ciência da computação, os pesquisadores da área podem obter informaçôes a respeito de como os consumidores se comportam em relação às suas práticas de consumo (Bercea, 2013).

Para Camargo (2009), o comportamento dos seres humanos é decorrente de um repertório comportamental resultante de dois componentes básicos: a interação da história evolutiva da espécie (filogenia) e a história evolutiva do indivíduo (ontogenia). O autor deixa claro seu posicionamento ao afirmar que náo se pode negar o evolucionismo do comportamento resultante da necessidade de sobrevivência e procriação, além das fortes influências do aprendizado, da relação corpo-ambiente, dos relacionamentos interpessoais, da geografia e de outros fatores que podem influenciar as açóes comportamentais de qualquer ser humano. Não há como desconsiderar que a evolução deixou marcas que os indivíduos carregam até hoje, visto que

se a anatomia tem relaçáo com a ancestralidade do cérebro e de todo o sistema nervoso, certamente, não se pode negar que a fisiologia também e junto com elas os neurotransmissores [...]. Por tanto, não é possível negar a influência da evolução no comportamento, que está diretamente ligado ao sistema nervoso (Camargo, 2009, p. 8).

Camargo (2009) complementa seu pensamento afirmando que não se pode desconsiderar, também, a existência do cérebro tri único no comportamento da espécie humana. Em termos evolucionistas, é 
possível dividir o cérebro em três partes, o que é conhecido pela neurociência, também, por cérebro triuno (Gonçalves, 2013). Neste trabalho, a divisão do cérebro em três partes segue a terminologia dos "três cérebros", utilizada por Klaric (2018). Esta teoria, baseada nas descobertas do neurocientista Paul D. McLean, divide o cérebro em três partes distintas: cérebro réptil, límbico e córtex.

Tal pensamento foi reforçado por Klaric (2018), visto que tal autor evidencia que os seres humanos estáo convencidos que sabem os motivos pelos quais adquirem algo, mas ninguém tem a menor ideia do porquê compramos alguma coisa, sendo, aquilo que acreditamos saber, apenas um resultado de processos cerebrais encadeados. O sistema nervoso age por vontade própria quando the é conveniente, além de reagir quando existem provocaçóes, que, ainda assim, é uma ação de um sistema dinâmico e não apenas de um objeto passível de ser moldado por, apenas, fatores externos (Camargo, 2009).

É neste contexto que o neuromarketing colabora com a pesquisa do comportamento do consumidor ao buscar a compreensão dos processos automáticos realizados pela mente sem a consciência deles, essas são decisóes mais rápidas ou que ocorrem com nenhuma ou com pouca percepção (Camargo, 2009).

Segundo Zaltman (2003), o pensamento de que os consumidores pautam, pela racionalidade, as suas decisóes e conduta é totalmente equivocada. Para Gonçalves (2013), as descobertas do rastreamento cerebral comprovaram que as decisôes de compra são açôes resultadas da genética humana funcionando em perfeita sincronia, sendo o que muitos pesquisadores já acreditavam e afirmavam.

Este rastreamento do cérebro humano permite identificar, no discurso implícito do consumidor, informaçôes "ocultas", apontando fatores determinantes do consumo (Ariely \& Berns, 2010). De acordo com Costa (2014), a análise da carga cognitiva, o envolvimento emocional, a memorizaçáo, a excitação, a atividade cerebral e o fluxo sanguíneo possibilitam avaliar as reações dos indivíduos mediantes estímulos do marketing. E, para rastreamento do cérebro humano, são usadas normalmente as seguintes ferramentas: imagem por ressonância magnética funcional (IRMF), eletroencefalografia (EEG), eyetracking e mensuração de respostas fisiológicas (Bercea, 2013).

A técnica de Imagens de Ressonância Magnética (IRMF) combina o campo magnético e ondas de rádio, produzindo um sinal que permite visualizar as estruturas cerebrais e acompanhar as atividades metabólicas de forma detalhada (Perrachione \& Perrachione, 2008). Já a Eletroencefalograma (EEG), que é uma das ferramentas mais utilizadas, após a IRMF, consiste na colocação de eletrodos no couro cabeludo em áreas específicas, com o objetivo de analisar a eletricidade de uma determinada área, conseguindo registrar as amplitudes das ondas cerebrais que podem corresponder a estados mentais, como, por exemplo, vigília, relaxamento, calma e sono (Bercea, 2013).

A outra ferramenta utilizada e mencionada é a Eye-Tracking, a qual faz um rastreamento ocular que permite medir o foco de atenção e, assim, monitorar tipos de comportamento (Laubrock et al., 2007). Zurawicki (2010) complementa que os movimentos oculares podem ser divididos em duas categorias: sacadas e fixaçóes; sendo a fixaçáo quando o movimento dos olhos faz uma pausa em certa posiçáo e a sacada em mudança para outra posição.

Klaric (2018) comenta que a tecnologia utilizada para criar estratégias de vendas é resultante da interação de várias outras tecnologias simultâneas, cujo objetivo é predizer o êxito ou o fracasso de discursos comerciais verbais, e, como consequência, ajudam a criar, melhorar e capacitar equipes de 
vendas. Valendo ressaltar que medidas mais fáceis e de custo mais baixo ainda são pouco comentadas, como o uso de medidas de níveis hormonais, de neurotransmissores, frequência cardíaca e respiratória, pressão arterial, intensidade de disparos elétricos musculares, entre outros (Lent, 2004).

A importância das técnicas e ferramentas do neuromarketing envolve o fato de que as metodologias tradicionais de pesquisa descobrem quanto e ondem comprar, mas não necessariamente o que motiva os consumidores (Camargo, 2009). Grande parte das pesquisas apenas confirma as certezas dos pesquisadores, não explorando novos conhecimentos; por isso, a inverdade de que os consumidores são capazes de compreender seus próprios processos mentais e que comportamentos continuam vivos nos pressupostos do marketing (Zaltman, 2003; Camargo, 2009).

Neste sentido, Peruzzo (2015) aponta que as pesquisas tradicionais possuem a limitação de acesso basicamente ao consciente e que o percentual de 5\% a 15\% das decisóes conscientes não é um percentual relevante. Para Camargo (2009), quando o indivíduo responde a um questionário, por exemplo, ele o faz com o uso do cérebro frontal (córtex), porém, as mais profundas verdades encontram-se no sistema límbico e reptiliano. Dessa forma, considerando que os consumidores não possuem acesso consciente aos recursos referentes às tomadas de decisóes, eles não podem explicar de forma clara como e por que razão eles as fazem, o que justifica os casos de insucessos de produtos lançados atualmente (Peruzzo, 2015).

No próximo tópico de discussão, apresentam-se conceitos a respeito dos "três cérebros" mencionados anteriormente: réptil, límbico e córtex, e suas influências nas decisôes dos consumidores.

\subsection{Um cérebro, três mentes: razão, emoção e instinto}

O pesquisador Paul D. MacLean (1952) obteve sucesso no campo da neurociência ao propor a teoria da existência e funcionalidade de três cérebros em um. Apesar de questionada, o desenvolvimento desta teoria vem demonstrando ser efetivo na delimitação e explicação de aspectos determinantes do comportamento humano (Klaric, 2018).

Estes três níveis cerebrais, sobrepostos progressivamente, funcionam de maneira conectada e interligada, possuindo características específicas, e sendo resultado de um percurso de milhóes de anos de evolução (Braidot, 2011). Para Peruzzo (2015), mesmo com a plasticidade e a possibilidade das funçóes cerebrais ocorrerem de forma simultânea e, ainda que existam céticos e críticos, é notório que uma área cerebral tem mais atividade que outra, comandando as decisóes nos processos racionais, emocionais e impulsivos; sendo, dessa forma, oportuno o conhecimento e a evolução das teorias que têm ligação com a lógica dos três cérebros.

Esta lógica divide o cérebro em três partes distintas: neocórtex, complexo límbico e reptiliano. Este último seria o cérebro mais primitivo, sendo a base do sistema de sobrevivência; o límbico, que se localiza acima do reptiliano, permite que os seres humanos sejam absolutamente emocionais; já o córtex, faz o processamento das informaçóes de maneira lógica (Klaric, 2018). A Figura 1 mostra como se configura o cérebro humano dividido em três partes, de acordo com o que fora proposto pela teoria de MacLean (1952). 


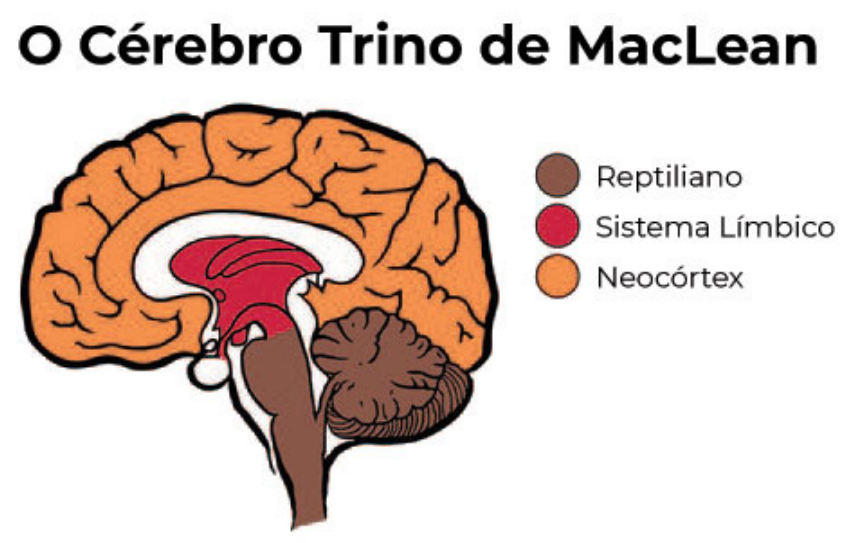

Fonte: Nova Escola de Marketing (2019).

O cérebro córtex é definido por Klaric (2018) como área de processamento de informação de maneira lógica e o autor aponta-o como um "local" em que se encontram muitos dos inibidores e dos controladores do comportamento. Pelo viés da teoria evolucionista, essa seria a região mais nova do cérebro humano (Camargo, 2009). Peruzzo (2015) define o neocórtex como um regulador de emoções do sistema límbico, sendo capaz de entender a linguagem simbólica e formal. Para Gonçalves (2013), o córtex é a camada que aciona as atividades cognitivas, sendo responsável pelo ato de pensar. Braidot (2011), por sua vez, define o córtex como o cérebro pensante, o nível mais recente da evoluçáo cerebral.

Peruzzo (2015) afirma que o complexo límbico possibilita que os processos de sobrevivência básicos do cérebro réptil interajam com os elementos externos do mundo, resultando na expressão da emoção geral, e, ainda, faz uma correlação com o superego de Freud, apontando que este possui uma consciência parcial e tem com funçáo orientar o ego, que o autor relaciona com o neocortex. Gonçalves (2013) comenta que o límbico é responsável por processar as emoçóes, transmitindo-as uma sensação positiva ou negativa para o reptiliano, preparando-o para uma decisão futura. Braidot (2011) complementa a definição ao informar que o sistema límbico é conhecido como o sistema das emoçóes, o qual possui funçôes importantes relacionadas à aprendizagem e à memória, e os medos, que são disparados diante estímulos.

O reptiliano, ou primitivo, é a camada mais profunda em que se operam as funçóes dos instintos e dos reflexos, como açôes de sobrevivência e atos sexuais (Gonçalves, 2013). Sendo a zona mais antiga, localizada de trás e baixa do crânio, possuindo o controle das condutas instintivas e emoçôes primárias (Braidot, 2011). Peruzzo (2015) compara o cérebro réptil com o ID de Freud, o qual é identificado como um reservatório inconsciente dos impulsos, focado no princípio de prazer.

\subsection{O poder dos cérebros reptiliano e límbico: inconsciente, instinto e emoção}

As decisóes são um conflito permanente, uma tensão entre os aspectos emocionais, do sistema límbico, e a capacidade de planejamento e racionalidade com a influência do cérebro reptiliano (Camargo, 2009). Há momentos em que o cérebro dos seres humanos é mais racional que emocional ou instintivo e o tempo de uma mudança de estado para o outro pode ser em milionésimos de segundo (Peruzzo, 2015). 
Considerando a divisão cerebral em três níveis, por exemplo, haverá estratégias que despertam, direcionam ou justificam a tomada de decisão de compra. Braindot (2011) exemplifica algumas estratégias baseadas em cada cérebro ao afirmar que: a compra de produto e serviços de seguros ou alarmes cresce quando há a sensação de insegurança, tendo como base o cérebro instintivo reptiliano; já as necessidades relacionadas com emoçáo (como o amor, reconhecimento, pertencimento a um grupo social) possuem origem no sistema emocional límbico; por outro lado, o cérebro pensante córtex interfere na decisão de compra quando os indivíduos analisam de forma consciente, através de uma lista comparativa de preço e características.

Neste trabalho, contudo, enfatizam-se as possíveis estratégias cujo foco envolve o cérebro reptiliano e límbico, os quais podem contribuir positivamente nas estratégias dos discursos de vendas, possibilitando a exploraçáo do inconsciente, do subconsciente, do instintivo e do emocional como ferramentas para atingir o objetivo final da venda.

Em 1983, foi descoberto que o cérebro consegue tomar decisóes antes mesmo de a pessoa tomálas de forma consciente (Camargo, 2009). Essa descoberta implica dizer que o cérebro decide antes do pensamento. $\mathrm{O}$ autor completa o pensamento ressaltando o poder do inconsciente e dos cérebros límbico e reptiliano para resultados de pesquisas:

95\% das informaçōes na nossa mente estão no inconsciente [...] nós seres humanos, temos uma tendência a mentir e ao autoengano e quando respondemos a uma pesquisa o fazemos com o córtex frontal, sendo que nossas "verdades" estão no sistema límbico e no cérebro reptiliano (Camargo, 2009, p. 29).

Para Klaric (2018), o cliente não sabe por que realiza uma compra de produto ou de serviço, pois $85 \%$ das decisôes de compras da vida de uma pessoa se dá de forma inconsciente, apenas os $15 \%$ restante sãos tomadas conscientemente. É a mente inconsciente e não a consciente que toma a decisão de compra de produtos, serviços ou ideias (Camargo, 2009), o que ressalta a importância do reptiliano para as estratégias de vendas. Afinal, o reptiliano é o cérebro que determina a compra, que toma a decisáo de comprar (Klaric, 2018). É ainda a parte cerebral responsável pelas decisóes de compras, sendo o ideal é que as mensagens publicitárias a atinjam diretamente (Gonçalves, 2013).

Para Klaric (2018), um grande vendedor não faz apenas o uso do cérebro reptiliano em cada momento, mas, também, tem a habilidade de saber ativá-lo em seus clientes; por isso, todos os vendedores deveriam aprender a vender ao cérebro réptil, pois ninguém compra nada senão por este cérebro, principalmente porque a emoção anula a razão, mas o instinto anula os dois. O autor define um "código réptil" ao afirmar que todos os produtos possuem uma necessidade réptil e que sempre há uma ligada ao instinto mais básico e mais biológico. Para chegar a esse código, Klaric (2018) afirma que a sua determinação para serviço ou produto deve ser relacionada ao mais instintivo, uma caraterística animal de princípios básicos, e que a lista desses códigos básicos dos seres humanos não chega a 30 questóes básicas, listando os códigos principais (os quais ele também denomina como botóes da venda réptil): anarquia, felicidade, controle, reprodução, dominação, prazer, segurança, união, proteção, união da tribo, movimento e exploração.

Peruzzo (2015) faz uma interligação do cérebro reptiliano com um personagem criado denominado "Macado", o qual é um potencial mental que comanda o instinto e tem base na genética, e afirma que este potencial representa a maioria absoluta das decisóes. A importância e poder desse potencial mental 
são afirmados pelo autor ao comentar que todo mundo toma decisóes por impulso, através da existência de estratégias para deixar o potencial mental que comanda a racionalidade e inteligência, denominado de Einstein, de lado.

Contudo, aspectos emocionais também possuem um papel importante no processo final de escolha, como, também, na formação de preferências e percepçôes de alternativas (Moreiral et al., 2011). Kenning e Plassmann (2005) acrescentam pontuando que muitas das decisões são, não apenas enviesadas, mas influenciadas pelas emoçôes. Moreiral et al., (2011, p. 104) complementam que

Umas das primeiras lições que a neurociência pôde fornecer é que o comportamento humano de tomada de decisão não é tão simples e aspectos emocionais possuem papel muito mais relevante na formulação de nossas decisóes do que se imaginava.

Segundo Klaric (2018), sempre deve haver a preocupação com o mais instintivo, mas quando a necessidade réptil ou instintiva é coberta, protegida, a etapa seguinte para é compreender as etapas de decisões, as quais envolvem três cenários diferentes, todos emocionais. Entre as três alternativas emocionais criadas, o cérebro escolhe racionalmente uma. $\mathrm{O}$ autor afirma que, efetivamente, as emoções podem fazer com quem um consumidor pague $20 \%$ ou $30 \%$ a mais por produtos similares, o que adiciona ainda mais importância às emoções (aqui, relacionadas com o cérebro límbico) nas decisóes de compra.

Faz-se oportuno ressaltar que há apelos em que os três cérebros são explorados com o objetivo da venda. O Quadro 1 apresenta um resumo da divisão cerebral, seguida pelas características e possíveis apelos, embasados na fundamentação teórica exposta, mais especificamente nos conceitos de Braidot (2011), Gonçalves (2013) e Peruzzo (2015).

Quadro 1 - Três cérebros, características e apelos

\begin{tabular}{|l|l|l|}
\hline \multicolumn{1}{|c|}{ Cérebro } & \multicolumn{1}{|c|}{ Características } & \multicolumn{1}{c|}{ Apelos } \\
\hline Neocórtex & $\begin{array}{l}\text { Inibidor, controlador e regulador de } \\
\text { emoçóes. Possibilita a ação cognitiva. É } \\
\text { responsável pela ação de pensar. }\end{array}$ & $\begin{array}{l}\text { Análise comparativa de produtos, preços, características. } \\
\text { Justificativo racional para a aquisição. }\end{array}$ \\
\hline Límbico & $\begin{array}{l}\text { Sistema processador de emoçóes e medos. } \\
\text { Subconsciente. }\end{array}$ & $\begin{array}{l}\text { Transforma emoçóes em sensaçóes positivas ou negativa, } \\
\text { direcionando o cérebro reptiliano. Permite a valorização do } \\
\text { produto. }\end{array}$ \\
\hline Reptiliano & Primitivo e instintivo. Inconsciente. & $\begin{array}{l}\text { Interliga as justificativas e tomadas de decisóes com } \\
\text { necessidades básicas e instintivas. }\end{array}$ \\
\hline
\end{tabular}

Fonte: Elaboração própria (2020).

Entretanto, Klaric (2018) direciona os profissionais para que “vendam à emoção" e traça o caminho para a efetivação de estratégias de vendas: identifique o código réptil; promova uma química no cérebro que resulte em emoção positiva que valorize o produto ou serviço e alcance a meta final de venda.

\section{Neurovendedores: estratégias para atingir a mente dos clientes}

As tomadas de decisões de compra são conflitos constantes, que envolvem a razão, a emoção, além da influência do cérebro reptiliano. Entretanto, o levantamento teórico aqui apresentado, enfatiza o poder que envolve os cérebros réptil e límbico para o comportamento do consumidor. Visto que os autores apresentados (Camargo, 2009; Gonçalves, 2013; Klaric, 2018) apontam que as estratégias de vendas 
devem focar em alcançar o cérebro réptil e límbico através de apelação instintiva e, em segundo plano, através da apelação emocional, sendo o cérebro réptil voltado ao instinto, o límbico a emoção e ambos envolvendo o pensamento inconsciente ou subconsciente.

Neste contexto, vale pontuar que o resultado final da tomada de decisão de compra requer muito do desempenho do vendedor. Segundo Klaric (2018), por exemplo, a importância do vendedor é ressaltada ao afirmado que saber agregar valor aos produtos para cumprir melhor as necessidades das pessoas, requer não só conhecer o público alvo, mas, também, saber se comunicar com ele e, muitas vezes, essa comunicação depende da comunicação estabelecida pelo vendedor.

Compreende-se que o vendedor deve fazer tudo, menos estar pensando na urgência de finalizar a venda. Klaric (2018) aponta que o princípio e a essência das neurovendas é "vender, sem vender". Os vendedores que utilizam os conhecimentos de neurovendas (neuromarketing) para potencializar o resultado em vendas se diferenciam dos vendedores tradicionais e utilizam a estratégia da venda não apelativa, sendo denominados como neurovendedore (Klaric, 2018). Esta nomenclatura também será a adotada neste trabalho.

Os neurovendedores vão além da venda tradicional, conseguem utilizar abordagem, linguagem e métodos eficazes para o desempenho da sua função. Há, sem dúvidas, uma diferença nas abordagens desses dois perfis de profissionais da área de venda, conforme apresentado no Quadro 2, seguindo as divergências apontadas por Klaric (2018).

Quadro 2 - Diferença entre vendedores tradicionais e neurovendedor

\begin{tabular}{|l|l|}
\hline \multicolumn{1}{|c|}{ Neurovendedor } & \multicolumn{1}{|c|}{ Vendedor tradicional } \\
\hline $\begin{array}{l}\text { Utiliza conscientemente palavras que atingem o cérebro } \\
\text { réptil, límbico e racional do cliente. }\end{array}$ & No discurso de vendas, utiliza palavras comuns. \\
\hline $\begin{array}{l}\text { Conta histórias, metáforas e analogias para exemplificar } \\
\text { benefícios. }\end{array}$ & Explica os benefícios do produto de forma direta e prática \\
\hline $\begin{array}{l}\text { Possui o conhecimento que as pessoas compram para } \\
\text { preencher vazios emocionais e suprir medos. }\end{array}$ & $\begin{array}{l}\text { Acredita que o mais importante para vender são as características } \\
\text { dos produtos }\end{array}$ \\
\hline $\begin{array}{l}\text { Faz uma análise do consumidor, adaptando o discurso a a } \\
\text { tipologia de cada um. }\end{array}$ & Possui um discurso genérico para todos os tipos de clientes. \\
\hline Aplica um discurso diferenciado para homens e mulheres. & Utiliza um discurso unissex. \\
\hline Comunica-se com o corpo. & Comunica-se com a boca. \\
\hline $\begin{array}{l}\text { Sabe da importância do conjunto dos cinco sentidos para a } \\
\text { decisão de compra. }\end{array}$ & Pensa que as palavras são as mais poderosas na negociação. \\
\hline $\begin{array}{l}\text { Leva em consideração que 85\% das decisóes são } \\
\text { inconscientes ou sub inconsciente. }\end{array}$ & $\begin{array}{l}\text { Identifica o racional como o que mais ajuda no processo da } \\
\text { venda }\end{array}$ \\
\hline Vende à mente das pessoas. & Vende às pessoas. \\
\hline
\end{tabular}

Fonte: Klaric (2018).

As estratégias expostas abaixo são inspiradas no trabalho de Klaric (2018), embasados com os achados da revisão de literatura de outros autores citados ao longo deste trabalho e correlacionadas com os cérebros límbico e réptil, da teoria dos três cérebros (por exemplo: Peruzzo, 2015; Braindot, 2011; 
Gonçalves, 2013; Camargo, 2009; Moreira et al., 2011; entre outras). Essas estratégias possibilitarão que os vendedores de pequenas ou médias empresas desempenhem a sua atividade com propriedade em conceitos da neurociência, conseguindo, dessa forma, alcançar uma posição de destaque em resultados. Afinal, utilizar os conhecimentos decorrentes do neuromarketing possibilita benefícios em vendas.

O poder do nome próprio é a primeira estratégia apontada por este estudo. A segunda pessoa do singular é o pronome que mais empodera o cliente em uma negociação de vendas (Klaric, 2018). Contudo, e indo um pouco mais além, o poder do nome próprio pode despertar ainda mais a atenção e dá poder ao consumidor. Se a utilização de pronomes pessoais (por exemplo: tu, você) ou pronomes de tratamento (ex: senhor, senhora) desperta a atenção, pode-se concluir que utilizar com uma frequência relativa o nome próprio do consumidor possibilita que o discurso de vendas passe do patamar de pessoal para único. É um indivíduo falando diretamente com outro, o qual possui tamanha importância que não se é possível esquecer o seu nome. Transmite a ideia de importância, de dominação. Ou seja, é o código réptil poder despertado, possibilitando uma conversa que desperta um dos botôes de vendas réptil de Klaric (2018).

Em outra perspectiva, destaca-se o pensamento do poder que pode envolver o nome próprio do vendedor. A apresentação com o nome próprio pode despertar o código réptil de segurança. Não é qualquer vendedor cujo objetivo é apenas finalizar uma compra e atingir número. É uma pessoa, com suas peculiaridades, com sua história, família, amigos e todos os atributos ligados ao indivíduo que está se apresentando para oferecer ajuda, tirar dúvidas, prestar uma consultoria. Podendo ser interligado com a confiança e, ao mesmo tempo em que atinge o cérebro réptil por meio da segurança, possibilita a relação com a emoção do cérebro límbico. Nesta estratégia, o vendedor tem a possibilidade de se tornar íntimo e a venda torna-se uma consequência de uma relação. Sendo a emoção e o instinto atingido no relacionamento de vendas.

A oportunidade de aproximação com o cliente possibilita a segunda estratégia: venda a um amigo. Em uma abordagem de relacionamento, a venda é consequência. Por isso, seja amigo/colega do seu cliente. Klaric (2018) comenta que se vende mais escutando que falando e ressalta o poder de realizar uma venda quando não se é nem comentado sobre a negociação. Por isso, as pessoas que sabem mais sobre o assunto que envolve o produto ou serviço vendem mais que as que não se interessam pelo tema; já as mais simpáticas comercializam mais em um processo de venda; porém, as que conseguem se relacionar com o cliente, em um contexto em que se não envolve nenhum assunto relacionado com o objetivo final da venda, seguramente resultará em resultados positivos (Klaric, 2018). Estando aqui a chave da estratégia: aproxime-se do seu cliente. Crie um relacionamento de amizade, fale de assuntos que vão além à negociação, seja um consultor, explore abordagens distintas do assunto principal, escute e espere a consequência: a efetivação da venda. Uma amizade construída possibilita atingir os botôes de vendas de união da tribo, aceitação social e despertar o sentimento de confiança, segurança. Alcançando, dessa forma, os cérebros réptil e límbico na negociação.

Explorar a sensação de medo é a terceira estratégia. Klaric (2018) aponta que tudo que se é comprado tem objetivo de reduzir de alguma forma os níveis de medos dos seres humanos, medos que geram carências e vazios, que podem ser preenchidos por marcas e produtos. O autor dá exemplos de medos supridos pelo consumo: compras de chocolate pelo medo de não seguir aproveitando a vida; compras de chiclete pelo medo de não ser aceito pelo odor da boca. Contudo, ainda esse pensamento, os 
vendedores não devem gerar medo que levem os consumidores a aliviá-lo com a aquisição do produto, mas devem conhecer os temores dos clientes para que ele possa apresentar a solução.

Então, correlacionar o produto, serviço ou marca com um medo inconsciente é uma estratégia que pode ser relacionada ao instintivo e ao emocional. $\mathrm{O}$ vendedor consegue atingir esse medo através do discurso de vendas. Klaric (2018) aponta outros medos que podem ser explorados: medo da desaprovação social, medo de não estar na moda, medo de perder a energia, etc. Correlacionamos este pensamento com exemplos práticos e comuns do dia a dia, como de fim de estoque, últimos modelos, peças únicas, últimas vagas, vagas limitadas, entre outros, os quais transmitem a ideia de urgência. Essas estratégias podem ser utilizadas com a consciência do poder que elas possuem para a mente do consumidor. Se um cliente já se idealizou utilizando um determinado serviço ou produto, mas, infelizmente, talvez ele não consiga adquirir porque não há mais, o medo é despertado e a solução é automaticamente suprida pelo vendedor que traz com um exemplar encontrado no estoque, traz o último ou único modelo disponível, reserva e garante a vaga no serviço limitado, entre outros exemplos.

Ir além da comunicação verbal é a quarta estratégia apontada por esse trabalho. Explorar todas as formas de se comunicar através do olhar, de gestos, de expressão corporal e movimentos é importante para a negociação de compra. Klaric (2018) comenta que o vendedor deve ver como se expressam as pessoas e utilizar os mesmos gestos para se conectar, gerando, assim, empatia e ativando os neurônios espelhos. Os neurônios espelhos, seguindo a definição do autor, são os grupos de células cerebrais que se ativam em resposta das expressóes não verbais de outra pessoa, permitindo que haja a experimentação das mesmas sensaçôes e emoçôes. A comunicação além da verbal, explorando apelos visuais e dos demais sentidos, se dá quando o vendedor olha para o produto, explora elementos visuais, convida o cliente a tocar, sentir, interagir, etc., no momento da negociação.

Dessa forma, comunicar-se de forma verbal e corporal com o consumidor, explorando os neurônios espelhos e os sentidos, pode direcionar o cliente à ação final de compra. Adaptar-se ao jeito da pessoa, direcionar o olhar para o produto que o cliente deve olhar, tocar o produto na frente do cliente são estratégias positivas. O vendedor deve, então, sorrir se o cliente for simpático, olhar no olho, adaptar-se à expressão corporal, explorar os cincos sentidos no ambiente e falar além das palavras.

As quatro estratégias apontadas podem ser exploradas de diversas formas no dia a dia das negociações de vendas e de maneiras sutis. Expressar-se de maneira corporal, principalmente facial, encontrar a solução do medo através do produto ou marca, criar um relacionamento além do comercial com o cliente e explorar o nome do cliente e do vendedor consegue atingir as áreas cerebrais reptiliana e límbica da teoria dos três cérebros, explorando o poder do instinto e da emoção nas decisóes de compra. No Quadro 3, visualizam-se resumidamente as estratégias trazidas derivadas da literatura e as práticas de vendas que podem ser aplicadas a elas. 
Quadro 3 - Estratégias e Práticas

\begin{tabular}{|c|l|}
\hline \multicolumn{1}{|c|}{ Estratégias } & \multicolumn{1}{|c|}{ Prática } \\
\hline O poder do vocativo & $\begin{array}{l}\text { O vendedor apresentar-se com o seu nome próprio; } \\
\text { Chamar o cliente pelo nome próprio ao longo da negociação; }\end{array}$ \\
\hline Vender a um amigo & $\begin{array}{l}\text { Relacionar-se com o cliente de forma mais pessoal; } \\
\text { Abordar assuntos que vão além da compra ao longo do processo de decisão; } \\
\text { Construir relaçóes de proximidade; }\end{array}$ \\
\hline Explorar os medos e receios & \begin{tabular}{l} 
Transmitir a ideia de urgência. \\
\hline Ir além da comunicação verbal
\end{tabular} \\
$\begin{array}{l}\text { Olhar nos olhos; } \\
\text { Expressar-se com o corpo; } \\
\text { Explorar os cinco sentidos; } \\
\text { Adequar-se à linguagem corporal do cliente. }\end{array}$ \\
\hline
\end{tabular}

Fonte: Elaboração própria (2020).

Estas estratégias e práticas, aqui apresentadas, envolvem apelos emocionais e instintivos, norteando métodos aplicáveis para vendedores de diversos tipos de produto ou serviço. Códigos reptilianos e emoçóes despertadas através de simples práticas do cotidiano de uma negociação de vendas que podem potencializar resultados, por meio da exploração de tomadas de decisóes resultantes de processos mentais não conscientes.

\section{Considerações finais}

Este estudo foi norteado pelo objetivo de apresentar uma reflexão sobre a influência dos cérebros reptilianos e límbico para resultados de vendas, buscando indicar o poder do instinto, inconsciente e da emoção para o discurso dos e vendedores, além da apresentação de estratégias de fáceis aplicaçôes para pequenas e médias empresas. Estas reflexôes e as estratégias e práticas apresentadas foram baseadas em conceitos e teorias do neuromarketing. Uma das teorias exploradas no trabalho foi a teoria dos três cérebros, que fraciona o cérebro em três distintos: o córtex, o límbico e o reptiliano.

Considerando, que, mesmo com o crescimento de pesquisas envolvendo a disciplina do neuromarketing, a interligação da temática com resultados e estratégias para vendas através da exploração de apelos cerebrais que envolvem o cérebro límbico e reptiliano ainda carece de publicaçôes, o que justifica a importância deste trabalho. A relevância do estudo envolve, também, a possibilidade de contribuir positivamente nos resultados de vendas de pequenas e médias empresas que utilizarem e absorverem as teorias e raciocínios expostos, por meio das estratégias de baixo custo, voltadas para o discurso presencial de vendas.

Como foi possível verificar, o estudo buscou embasamento teórico para exposição de conceitos e teorias da disciplina do neuromarketing. Ao possuir um status de nova disciplina, o neuromarketing entrega informaçóes valiosas para compreensão do comportamento do consumidor e dos processos de decisóes de compra. A partir das tecnologias e avanços científicos, as neurociências permitiram a análise comportamental sob uma perspectiva cerebral, que é muito valiosa para o marketing, visto que o rastreamento cerebral identifica informaçôes "ocultas" no discurso implícito do consumidor, preenchendo, 
dessa forma, uma lacuna das pesquisas tradicionais do marketing, limitadas pelo acesso basicamente ao consciente do consumidor.

Este trabalho considerou, também, outros aspectos que influenciam o comportamento dos consumidores. Consideraçóes de autores apresentados embasaram o raciocínio que correlaciona o comportamento da espécie humana com aspectos evolutivos da espécie e o indivíduo. Dessa forma, a necessidade de sobrevivência e procriação (instinto), o aprendizado, da relação com ambiente e com outros indivíduos foram apontados como pontos importantes para a análise comportamental e, consequentemente, para a elaboração de estratégias. Neste contexto, a teoria dos "três cérebros" foi apresentada e norteou a elaboração das estratégias.

A divisão cerebral em três partes diferentes, ainda que questionada, pode ser correlacionada com outras teorias comportamentais e, conforme o pensamento de Klaric (2018), demonstra ser efetiva na delimitação e explicação de aspectos determinantes do comportamento. Os autores explicam a divisão dos três cérebros, correlacionando o cortéx com a razão e cognição; o límbico com o processamento das emoçôes; e o reptiliano com aspectos primitivos e instintivos.

Há a compreensão da importância dos cérebros límbicos e reptiliano para a análise do comportamento do consumidor, visto que a grande maioria da tomada da decisão de compra seja resultante de processos mentais não conscientes. Desta forma, a emoção e aspectos instintivos possuem poder no discurso de vendas. Em um aspecto de relevância, o instinto ocuparia o lugar principal, seguido pela emoção e, por fim, a razão. O que direciona a possibilidade de elaboração de estratégias para apelos efetivos no discurso de vendas.

Após esta reflexão, estratégias de fáceis aplicaçôes foram determinadas e interligadas com o estudo do pesquisador Jurgen Klaric, chegando-se à conclusão que o poder da utilização de vocativo (principalmente do nome próprio do vendedor ou cliente), a aproximação e o relacionamento do vendedor com o cliente de uma maneira mais íntima e ampla, a exploração dos medos e receios do cliente por parte do vendedor e a comunicação entre eles através de diversas linguagens (verbais ou não) possibilitam atingir os cérebros reptiliano e límbico, por meio da emoção e do instinto, indo além às percepçóes consciente do consumidor. O que indica a possibilidade de resultados positivos na tomada de decisão de compra, conforme conceitos e pensamentos apresentados e discutidos.

Entretanto, este estudo também revelou o potencial a ser explorado de pesquisas que testem a relevância dos resultados da abordagem emocional e instintiva, além das estratégicas apresentadas. Como recomendaçóes para futuras pesquisas, indicamos que as consideraçóes trazidas por este trabalho em relação as estratégias de vendas sejam aplicadas na realidade de pequenas e médias empresas. Compreendemos que poderia ser proposto um modelo teórico que visasse verificar quais estratégias seriam mais eficazes em um modelo de regressão linear, considerando o crescimento de vendas como variável dependente.

Dessa forma, ao testar empiricamente o que fora constatado pela revisão de literatura, pesquisadores poderiam se debruçar melhor sob a influência do cérebro humano no comportamento do consumidor, trazendo novos insights para as neurociências e, consequentemente, trabalhar posicionamentos mercadológicos que permanecem como preocupação para o marketing gerencial. Também é indicado que estudos futuros considerem as implicaçôes éticas da utilização do neuromarketing nas estratégias mercadológicas, a partir de visóes dos consumidores e não apenas da perspectiva gerencial. 


\section{Referências}

Ariely, D., \& Berns, G. S. (2010). Neuromarketing: the hope and hype of neuroimaging in business. Nature reviews neuroscience, 11(4), 284.

Bercea, M. D. (2013) Quantitative versus qualitative in neuromarketing research. Munich Personal RePEc Archive. Disponível em: https://mpra.ub.uni-muenchen.de/44134/. Acesso em: 04 jun. 2020.

Boricean, V. (2009). Brief history of neuromarketing. In: ICEA-FAA. The International Conference on Economics and Administration. Faculty of Administration and Business, University of Bucharest, Romania, p. 14-15.

Braidot, N. (2011). Neuromarketing en acción. Ediciones Granica SA.

Camargo, P. (2009). Neuromarketing: Descodificando a mente do consumidor. Ediçóes IPAM.

Chorvat, T., \& McCabe, K. (2005). Neuroeconomics and rationality. Chi.-Kent L. Rev., 80, 1235.

Costa, C. (2014) A pesquisa de Marketing que veio para ficar. Revista Meio e Mensagem, p. 24. Disponível em: http://www.scielo.br/pdf/tce/v15n4/v15n4a17. Acesso em: 04 jun. 2020.

Garcia, J. R., \& Saad, G. (2008). Evolutionary neuromarketing: Darwinizing the neuroimaging paradigm for consumer behavior. Journal of Consumer Behaviour, 7(4囚5), 397-414.

Gonçalves, L. S. (2016). Neuromarketing Aplicado à Redação Publicitária: Descubra como atingir o subconsciente de seu consumidor. Novatec Editora.

Holley, K. A. (2006). The cultural construction of interdisciplinarity: Doctoral student socialization in an interdisciplinary neuroscience program. ProQuest Information and Learning Company.

Kenning, P., \& Plassmann, H. (2005) NeuroEconomics: An overview from an economic perspective. Brain Research Bulletin, 67, p.343-354.

Klaric, J. (2018). Vende a la mente, no a la gente: Neuroventas. La ciencia de vender más hablando menos. Editorial Planeta.

Laubrock, J., Engbert, R., Rolfs, M., \& Kliegl, R. (2007). Microsaccades are an index of covert attention: commentary on Horowitz, Fine, Fencsik, Yurgenson, and Wolfe (2007). Psychological Science, 18(4), 364-366.

Lent, R. (2004) Cem bilhóes de neurônios: conceitos fundamentais de neurociência. São Paulo: Atheneu.

Maclean, P. D. (1952). Some psychiatric implications of physiological studies on frontotemporal portion of limbic system (visceral brain). Electroencephalography \& Clinical Neurophysiology, 4, p.407418. 
Moreiral, B. C. M., Pacheco, A. F. A., \& Barbato, A. M. (2011). Neuroeconomia e neuromarketing: imagens cerebrais explicando as decisões humanas de consumo. Ciências \& Cognição, 16(1).

Morin, C. (2011). Neuromarketing: the new science of consumer behavior. Society, 48(2), 131-135.

Neurobusiness Association (2015). Disponível em: <https://neurobusiness.org/>. Acesso em: 22 jan. 2019.

Nova Escola de Marketing (2019). O Cérebro trino, reptiliano, límbico e neocortex.

Disponível em: <https://novaescolademarketing.com.br/neuromarketing/o-cerebro-trino-reptilianolimbico-e-neocortex/>. Acesso em: 05 fev. 2019.

Perrachione, T. K., \& Perrachione, J. R. (2008). Brains and brands: Developing mutually informative research in neuroscience and marketing. Journal of Consumer Behaviour, 7(4囚5), 303-318.

Peruzzo, M. (2015). As três mentes do neuromarketing. Alta Books Editora.

Solnais, C., Andreu-Perez, J., Sánchez-Fernández, J., \& Andréu-Abela, J. (2013). The contribution of neuroscience to consumer research: A conceptual framework and empirical review. Journal of Economic Psychology, 36, 68-81. Disponível em: https://core.ac.uk/download/pdf/76992554.pdf. Acesso em: 04 jun. 2020.

Zaltman, G. (2003). Afinal, o que os clientes querem? o que os consumidores e os concorrentes não sabem. Campus.

Zurawicki, L. (2010). Neuromarketing: Exploring the brain of the consumer. Springer Science \& Business Media. 